\title{
Vigilar y castigar: el papel de militares, policías y guardias civiles en la comunicación de la crisis del Covid-19 en España
}

\author{
Discipline and punish: the role of the military, police and \\ civil guards in communicating the Covid-19 crisis in Spain
}

\author{
Guillermo López-García
}

Cómo citar este artículo:

López-García, Guillermo (2020). "Vigilar y castigar: el papel de militares, policías y guardias civiles en la comunicación de la crisis del Covid-19 en España". El profesional de la información, v. 29, n. 3, e290311.

https://doi.org/10.3145/epi.2020.may.11

Artículo recibido el 08-05-2020 Aceptación definitiva: 16-05-2020

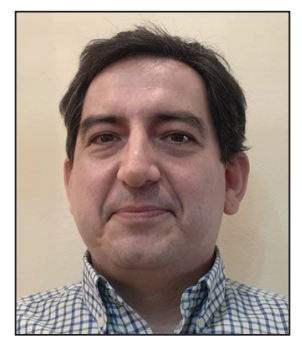

\author{
Guillermo López-García $\bowtie$ \\ https://orcid.org/0000-0002-5701-2024 \\ Universitat de València, Departamento de Teoría \\ de los Lenguajes y Ciencias de la Comunicación \\ Av. Blasco Ibáñez, 32. 46010 Valencia, España \\ guillermo.lopez@uv.es
}

\section{Resumen}

Se analiza el papel de las Fuerzas Armadas y las Fuerzas y Cuerpos de Seguridad del Estado españolas como actores y como recurso discursivo en la comunicación del Gobierno español durante la crisis del Covid-19. El análisis abarca dos cuestiones complementarias. Por una parte, la presencia de militares, policías y guardias civiles en los medios de comunicación y en las ruedas de prensa diarias del Comité de Gestión Técnica de la crisis del coronavirus desde el Gobierno español. Por otra parte, el discurso en Twitter de los principales protagonistas políticos de la crisis en España: los líderes de los cinco partidos de ámbito nacional con grupo parlamentario ( $P S O E, P P$, Vox, Unidas Podemos y Ciudadanos) y los presidentes de cuatro comunidades autónomas (Cataluña, Madrid, Comunidad Valenciana y País Vasco) que también cumplen un papel particularmente importante en la gestión de esta crisis. El marco temporal abarca desde el 15 de marzo (inicio del estado de alarma) hasta el 25 de abril (último día en el que participan FFAA y FCSE en la rueda de prensa diaria del Comité Técnico). La metodología que se aplica a este material es doble: un análisis cualitativo de las apariciones de FFAA y FCSE en medios de comunicación y en las ruedas de prensa del Comité Técnico, que permite esbozar un relato complejo de los acontecimientos; y un análisis de contenido de las cuentas de Twitter anteriormente mencionadas, que muestre la presencia de dichos colectivos y del lenguaje bélico en sus mensajes. Los objetivos son hacer un doble balance de la estrategia de comunicación del Gobierno en relación con la presencia de militares, Guardia Civil y Policía Nacional: interno (en las ruedas de prensa) y externo (en los medios y, en particular, en el discurso de los dirigentes políticos).

\section{Palabras clave}

Covid-19; Coronavirus; Pandemias; Comunicación de crisis; Fuerzas armadas; Fuerzas de seguridad; Policía Nacional; Guardia Civil; Crisis sanitaria; Comunicación institucional; Gobierno de España; Estado de alarma; Twitter; Comunicación política.

\section{Financiación}

Este artículo forma parte del proyecto financiado por el Ministerio de Economía y Competitividad español "Estrategias, agendas y discursos en las cibercampañas electorales: medios de comunicación y ciudadanos” (2017-2020). Referencia CSO2016-77331-C2-1-R. 


\begin{abstract}
This article analyzes the role of the Spanish Army and Security Forces as actors and as a discursive resource in the Spanish Government's communication during the Covid-19 crisis and covers two complementary questions. On one hand, the presence of the military, police and civil guards in the media and in the daily press conferences of the Spanish Government's Coronavirus Crisis Committee and, on the other, tweets by the main political protagonists of the crisis in Spain: the leaders of the five largest national parties ( $P S O E, P P, V o x$, Unidas Podemos and Ciudadanos) and the presidents of four autonomous communities (Catalonia, Madrid, the Valencian Community and the Basque Country) who also played a particularly important role in managing the crisis. The timeframe covered is from March 15 (start of the state of emergency) to April 25 (final day in which the military and security forces participated in the daily press conferences of the Coronavirus Crisis Committee). The methodology applied involves a qualitative analysis of the appearances by military and security forces in the media and in the press conferences of the aforementioned Committee, which allows us to outline a complex narrative of the events. A content analysis of the Twitter accounts is also performed to show the presence of these groups and the warlike language in their messages. The objectives are to balance the Government's communication strategy in relation to the presence of the military, the Civil Guard and the National Police: internally (at press conferences) and externally (in the media and, in particular, in speeches by political leaders).
\end{abstract}

\title{
Keywords
}

Covid-19; Coronavirus; Pandemics; Crisis communication; Spanish army; Security forces; Spanish police; Civil Guard; Health crisis; Institutional communication; Government of Spain; State of emergency; Twitter; Political communication.

\section{Introducción: militares y fuerzas de seguridad en la crisis del Covid-19}

"La gran crisis de nuestras vidas". Así se ha referido en repetidas ocasiones el presidente del Gobierno de España, Pedro Sánchez, a la crisis generada en todo el mundo por la pandemia del coronavirus SARS-CoV-2, que provoca la enfermedad Covid-19. Se trata, en efecto, de una crisis de gran magnitud, que además afecta a todos los órdenes de la vida (a la salud, pero también a la economía y a nuestra manera de vivir). Y, en consecuencia, las estrategias de comunicación de dicha crisis desarrolladas desde las instituciones resultan también de gran relevancia social y académica.

En el caso del Gobierno español, los ejes de su estrategia de comunicación de la crisis del Covid-19, sintetizando mucho, han sido hasta ahora cuatro:

1) Comunicación continua: la comunicación emanada desde el Gobierno ha sido constante a lo largo de toda la crisis: ruedas de prensa diarias del Comité de Gestión Técnica de la crisis del coronavirus, liderado por el doctor Fernando Simón; comparecencias diarias de ministros del Gobierno; comparecencias semanales del presidente Pedro Sánchez.

2) Gravedad de la crisis: desde la instauración del estado de alarma, con unas medidas restrictivas de las libertades ciudadanas prácticamente sin parangón en otros países de nuestro entorno (de dureza sólo comparable al caso italiano), el Gobierno español ha enfatizado constantemente la gravedad de la pandemia del coronavirus como mecanismo de concienciación ciudadana, pero también como estrategia discursiva que busca justificar las insuficiencias o errores en la gestión del Gobierno, así como ponerlos en perspectiva como deficiencias compartidas con la mayoría de los países occidentales, que tampoco se prepararon adecuadamente para hacer frente a la pandemia, y se vieron hasta cierto punto superados por los acontecimientos.

3) Sensación de control: en combinación con el mensaje anterior, las palabras, y también las acciones del Gobierno español han buscado establecer en los ciudadanos la percepción de que el Gobierno controlaba la crisis; que había alguien al mando, con unas directrices claras; y que aquellos ciudadanos o actores políticos que no aceptasen las medidas adoptadas en respuesta a la gravedad de la crisis, no tendrían más remedio que hacerlo ante las disposiciones del Gobierno para controlar la situación: centraliza la gestión de la crisis y asume el control sobre las competencias de las Comunidades Autónomas, así como la restricción de las libertades que supone la declaración del estado de alarma.

Amat et al. (2020) analizan los resultados de una encuesta a ciudadanos españoles desarrollada a finales de marzo, en los días más difíciles de la primera oleada de la pandemia, que muestra cómo, dado el carácter excepcional de la crisis, una mayoría de la población está dispuesta a renunciar a sus libertades para contener el virus. También se observa una clara preferencia por acometer la respuesta a la crisis desde un marco nacional, encarnada en liderazgos fuertes. Un análisis que se ajusta muy claramente al enfoque de la comunicación de esta crisis por parte del Gobierno español, así como a su asunción de competencias autonómicas para centralizar la respuesta a la crisis.

4) Unidad: finalmente, y como consecuencia lógica de lo que antecede, el discurso gubernamental ha apelado constantemente a la unidad y a la superación de conflictos y discrepancias políticas, en pro de superar esta crisis. Se trata de un movimiento previsible en la gestión de este tipo de acontecimientos, que pueden resultar extraordinariamente beneficiosos, en términos políticos, para quienes encarnan el liderazgo en la respuesta a la crisis. Se trata del efecto "round the flag", definido inicialmente en relación con el papel de los presidentes de EUA en conflictos interna-

En las guerras, hay que hacer sacrificios. Hay que estar unidos. Y hay que sacrificar libertades 
cionales (Mueller, 1970): en situaciones de adversidad e incertidumbre, el público tiende a reunirse en torno a las figuras de autoridad, buscando protección. Un efecto que explica el aumento de la popularidad de la mayoría de los líderes mundiales en la crisis del coronavirus; aunque no haya sido así, por el momento, en el caso de Pedro Sánchez (Magnet, 20 de abril de 2020: “Merkel sube; Sánchez baja: cómo está afectando el coronavirus a la popularidad de los gobiernos»).

La comunicación del gobierno en esta crisis, como se intuye fácilmente, puede analizarse desde muchas perspectivas. En este artículo, me centraré en una cuestión muy específica, pero creo que en absoluto menor: el papel de las Fuerzas Armadas españolas, la Policía Nacional y la Guardia Civil, en la estrategia de comunicación llevada a cabo por el Gobierno español. Si bien la comunicación de los militares y miembros de las fuerzas de seguridad es un campo ampliamente estudiado (Campo-Fort et al., 2016; Ibáñez, 2016), no puede decirse lo mismo de su participación en situaciones de crisis de esta naturaleza. Entre otros factores, precisamente por ello, por lo insólita que resulta su relevancia en la estrategia de comunicación del Gobierno, se antoja una materia de estudio tan interesante.

Su presencia se plasmó, sobre todo, en las ruedas de prensa diarias del Comité de Gestión Técnica de la crisis del coronavirus, donde eran mayoría (tres de cinco participantes); en el lenguaje empleado por parte de los portavoces gubernamentales, y en especial el presidente del Gobierno, Pedro Sánchez, con abundantes metáforas bélicas; y en la presencia de las acciones de los militares, la policía y la Guardia Civil en los medios de comunicación.

La visibilidad de las Fuerzas Armadas (en adelante, FFAA) y Fuerzas y Cuerpos de Seguridad del Estado (en adelante, FCSE) contribuye desde diversos puntos de vista a la estrategia comunicativa del Gobierno español:

- Permitiría beneficiarse de su popularidad. Tanto las FFAA como las FCSE (Policía y Guardia Civil) son instituciones populares para los ciudadanos españoles, según muestran sistemáticamente las encuestas. Por ejemplo, en el último estudio del Centro de Investigaciones Sociológicas que preguntó sobre esta cuestión (CIS, 2015) se llega al resultado, de hecho, de que son las más populares, entre un variado elenco de instituciones valoradas por los españoles (tabla 1).

Puede percibirse con claridad el contraste entre la valoración de las FFAA y las FCSE y la de los partidos políticos, que ocupan el último lugar de la tabla, o del Gobierno español (antepenúltimo).

Se trata, sin duda, de un estudio que ya tiene cinco años de antigüedad. Pero las encuestas realizadas recientemente por diversos medios de comunicación, con motivo de la crisis del coronavirus, abundan en la misma tónica. Por ejemplo, la

Tabla 1. Confianza de los españoles en las instituciones. Fuente: CIS. Estudio 3080, Barómetro de abril de 2015.

\begin{tabular}{|l|c|}
\hline \multicolumn{1}{|c|}{ Institución } & Valoración / confianza \\
\hline Guardia Civil & 6,02 \\
\hline Policía Nacional & 5,95 \\
\hline Fuerzas Armadas & 5,51 \\
\hline Medios de comunicación & 4,57 \\
\hline Monarquía & 4,34 \\
\hline Defensor del Pueblo & 3,96 \\
\hline Iglesia católica & 3,61 \\
\hline Consejo General del Poder Judicial & 3,54 \\
\hline Tribunal Constitucional & 3,40 \\
\hline Gobierno de su comunidad autónoma & 3,20 \\
\hline Organizaciones empresariales & 3,19 \\
\hline Parlamento de su comunidad autónoma & 3,14 \\
\hline Parlamento & 2,83 \\
\hline Gobierno & 2,77 \\
\hline Sindicatos & 2,61 \\
\hline Partidos políticos & 2,23 \\
\hline
\end{tabular}

encuesta de Sociométrica (El español, 2 de abril de 2020: "Personal sanitario, Policía, Guardia Civil y Ejército, las instituciones mejor valoradas en plena crisis"), valora con un 8,3 a la Policía y la Guardia Civil, y con un 8,1 al Ejército, sólo por detrás del personal sanitario (9,4). La encuesta de Ipsos para el Grupo Henneo (Heraldo de Aragón, 15 de abril de 2020: "El Ejército, la institución mejor valorada en esta crisis") considera a las FFAA y FCSE los colectivos que mejor están actuando de cara a la crisis, con un $75 \%$ del público que valora positivamente su actuación (esta encuesta no incluye al personal sanitario). Por contraste, sólo un $24 \%$ piensa que el Gobierno español lo estaba haciendo bien o muy bien. Finalmente, la encuesta de 40dB (El país, 19 de abril de 2020: "Un 59\% de los españoles apoya el confinamiento más estricto") indica que un $68,4 \%$ de los encuestados valora mejor a la Policía que antes del estallido de la crisis, por un $65 \%$ al Ejército. De nuevo, se trata de las instituciones mejor valoradas (o, en este caso, cuya valoración mejora más) tras el personal sanitario (86\%).

En resumen: FFAA y FCSE son instituciones muy bien consideradas por los españoles, cuya opinión, además, mejora durante la crisis. Parece un factor de peso para que el Gobierno español intentase incorporarlas a su estrategia de comunicación.

- Protegerse de las críticas de la oposición: dada la popularidad de FFAA y FCSE, su vinculación con la acción del Gobierno español podría desactivar o minimizar las críticas que dicho Gobierno recibiera desde las demás fuerzas políticas, 
que en todo caso tendrían complicado justificar ante sus electorados, en la mayoría de los casos, poner en duda la labor de instituciones tan bien valoradas. Esto resultaría particularmente cierto en el caso de los partidos conservadores de ámbito nacional ( $P P$, Ciudadanos y Vox), cuyo electorado, según el mencionado estudio del CIS (2015), es el que mejor valora tanto a las FFAA como a la Policía y la Guardia Civil.

- Privilegiar la imagen de control y vigilancia de la población durante el Estado de Alarma: por último, parece razonable suponer que la presencia constante, en las noticias y en la comunicación emanada desde el Gobierno español, de las acciones de FFAA y FCSE (que en buena medida se centran en labores coercitivas) busca generar en la población una imagen de supervisión estrecha de las acciones de los ciudadanos, de control absoluto del confinamiento durante el estado de alarma, así como constatar la gravedad de la crisis y su carácter singular.

\section{Marco teórico}

La comunicación de crisis es un campo de análisis muy amplio y en constante evolución (Moreno-Castro, 2009). Por su propia naturaleza, la comunicación de crisis ha de adaptarse a circunstancias imprevistas y continuamente cambiantes. Existen muchos manuales sobre cómo operar en situaciones de crisis, que distinguen diversas fases en su evolución y analizan las necesidades comunicativas en cada una de ellas (Yan; Pang; Cameron, 2006). Pero estas hojas de ruta (como ocurre con las operaciones militares) rara vez resisten el contacto con la realidad, con el "enemigo", siguiendo la terminología bélica que va a acompañarnos a menudo en esta investigación. Sobre todo, en una crisis como la que nos ocupa, que no tiene precedentes (Xifra, 2020), o son muy lejanos en el tiempo (la "gripe española" de 1918-19).

Por ese motivo, entre otros, parece razonable la estructuración de las situaciones de crisis establecida por Coombs (2014), en tres fases: pre-crisis, crisis y post-crisis, que, como puede deducirse fácilmente, es posible aplicar a circunstancias muy diversas. La primera fase se centra en las acciones encaminadas a la detección, prevención y preparación de la crisis. La segunda abarca todas las acciones que la organización (en este caso, el Gobierno) lleva a cabo para gestionar la crisis hasta que ésta llega a su fin. Es en esta segunda fase en la que la comunicación de la crisis tiene particular relevancia. Por último, en la fase post-crisis la organización evalúa la eficacia de las distintas acciones llevadas a cabo durante la crisis y toma medidas para prepararse mejor de cara a futuros acontecimientos de índole similar.

No hay recetas para una situación como ésta. Ninguna crisis es igual a la anterior

Indudablemente, la crisis del Covid-19 dista mucho de haberse resuelto en España en el momento en que se escriben estas líneas (mediados de mayo de 2020). Podría afirmarse, teniendo en cuenta las cifras (de contagiados, fallecidos y curados) y las medidas adoptadas por el Gobierno para iniciar la desescalada en el confinamiento de la población, que se ha superado la fase aguda de la crisis (en esta primera oleada de la enfermedad, que probablemente no será la última); pero no la crisis en sí.

Una crisis de esta magnitud es un desafío para cualquier gobierno. Se trata de una ocasión en la que los ciudadanos valoran la gestión de sus gobernantes con criterios que van mucho más allá de los meramente partidistas. La evaluación de dicha gestión, además, no depende únicamente de los resultados que se alcancen, sino de la comunicación elaborada desde el gobierno a lo largo de la crisis (Canel, 2009). Por eso es tan importante acertar con las claves de la estrategia comunicativa, del mensaje que se busca transmitir a los ciudadanos y de los procedimientos empleados para transmitir dicho mensaje (Lee, 2009). En este sentido, es interesante valorar también el uso que se hace, en la crisis, de las metáforas bélicas, muy abundante en lo que se refiere a las comparecencias del presidente Pedro Sánchez y otros representantes del Gobierno español. El uso de todo tipo de metáforas es una estrategia retórica habitual en comunicación política (Capdevila; Moragas-Fernández, 2019), pero resulta particularmente llamativa su naturaleza bélica en una pandemia en la que el "enemigo" es un virus (Chiang; Duann, 2007).

La importancia de la crisis y el confinamiento de la población conducen a un contexto de sobreexposición mediática (Casero-Ripollés, 2020), en la que la atención ciudadana está volcada hacia todo lo relacionado con la crisis del Covid-19, que invade casi todos los rincones de los medios de comunicación (Lázaro-Rodríguez y Herrera-Viedma, 2020), como ha invadido también la vida de los ciudadanos. Los medios cumplen, como siempre, la doble función de informar y de entretener.

La importancia de la televisión y de los medios tradicionales ha venido decreciendo en los últimos años, por efecto de la diversificación de medios, la aparición de medios digitales que se erigen en complemento e incluso en dieta mediática única para un porcentaje significativo de la población (Casero-Ripollés, 2020), y la configuración, en última instancia, de un sistema mediático híbrido (Chadwick, 2013) en el que conviven medios convencionales y digitales y que, de hecho, se realimentan mutuamente.

Sin embargo, según indica Xifra (2020), los medios tradicionales se convierten, en crisis como esta, en "medios refugio", al modo en como ocurre con el oro y con las divisas más fuertes en las crisis económicas. En este sentido, Casero-Ripollés (2020) resalta el aumento del consumo de información política en Estados Unidos desde el inicio de la crisis. Un aumento que, además, fue mucho más significativo en el caso de los ciudadanos que menos consumen habitualmente contenidos informativos (un 62\% más), y que se centra sobre todo en la televisión (Besalú, 2020), cuyos programas informativos alcanzan grandes audiencias, sostenidas en el tiempo, dado el insaciable (y lógico) interés del público por 
obtener información relativa a la crisis del coronavirus. Lázaro-Rodríguez y Herrera-Viedma (2020) dejan asimismo constancia del enorme volumen de información sobre esta crisis generado en la prensa digital, sobre todo a raíz de la instauración del estado de alarma.

Las redes sociales, indudablemente, también cumplen un papel crucial en este proceso de comunicación. Las redes funcionan como mecanismo de reverberación, discusión y evaluación (Suau et al., 2017) de las medidas gubernamentales, en una situación excepcional en la que el público apenas cuenta con otras vías para manifestar su apoyo o desacuerdo, más allá de eventuales convocatorias de aplausos o caceroladas desde los balcones.

Desde esta perspectiva, el análisis de Twitter como medio de difusión de mensajes políticos resulta extraordinariamente útil para obtener una perspectiva general de las estrategias discursivas de cualquier partido político o candidato (Campos-Domínguez, 2017). Por su carácter abierto, su capacidad para fijar la agenda y captar la atención del público, así como por su naturaleza (mensajes breves, que se difunden rápidamente y que pueden viralizarse a través de vías muy diversas), Twitter constituye, sin duda, una de las redes sociales mejor adaptadas a la naturaleza de la comunicación política, que es la interrelación entre tres actores (políticos, medios de comunicación y ciudadanos) en un mismo espacio (López-García, 2017).

Por esta razón, hemos considerado necesario incorporar también un análisis de mensajes publicados en Twitter por parte de los principales líderes políticos españoles durante esta crisis que nos permita observar, por un lado, cómo se refleja la estrategia comunicativa del gobierno y, por otro lado, en qué medida los dirigentes de la oposición política se suman a dicha estrategia o, por el contrario, elaboran discursos alternativos.

\section{Hipótesis y metodología de análisis}

Esta investigación busca analizar un componente en apariencia secundario de una crisis sanitaria de gran envergadura, como es el caso de la pandemia del Covid-19: el papel de las FFAA y las FCSE en la política de comunicación del Gobierno responsable de gestionar la respuesta a la pandemia y su presencia en los medios de comunicación social y en el discurso de los partidos políticos. La razón última que justifica dicho análisis es la llamativa presencia de representantes de FFAA y FCSE, tanto en las ruedas de prensa diarias del Comité de Gestión Técnica de la crisis del coronavirus como en la estrategia general del Gobierno, así como en los medios de comunicación. Una presencia que no creemos en absoluto casual, sino producto de una decisión estratégica que tiene mucho que ver con la comunicación que ha buscado desplegar el Gobierno español en esta crisis.

En consecuencia, nuestra hipótesis de partida es la siguiente: el Gobierno privilegia la presencia comunicativa de FFAA y FCSE para lograr determinados objetivos en su estrategia de comunicación; pero las limitaciones comunicativas de los portavoces de FFAA y FCSE le acaban generando más problemas que beneficios al Gobierno, razón por la cual se prescinde de su participación en las ruedas de prensa del Comité de Gestión Técnica de la crisis del coronavirus.

Como veremos en el análisis, dichas limitaciones se manifiestan desde diversos puntos de vista, y en algunas ocasiones se convierten incluso en noticias de cariz negativo, obviamente no buscadas por el Gobierno.

En relación con esta hipótesis, se plantean tres preguntas de investigación:

P1: ¿Cómo se refleja la actividad de FFAA y FCSE en los medios de comunicación?

P2: ¿Qué y cómo comunican los FFAA y FCSE en las ruedas de prensa del Comité de Gestión Técnica de la crisis del coronavirus?

P3: ¿Cómo evalúan los líderes políticos españoles las acciones de FFAA y FCSE?

Las preguntas de investigación buscan perfilar mejor el análisis del papel de FFAA y FCSE en esta fase aguda de la crisis, y se corresponden casi exactamente con el corpus que hemos seleccionado. Dicho corpus abarca un marco temporal amplio, de 41 días: desde el 15 de marzo hasta el 25 de abril de 2020, ambos inclusive. Es decir, desde el inicio del estado de alarma hasta la última de las comparecencias del Comité de Gestión Técnica de la crisis del coronavirus en la que participan representantes de FFAA y FCSE. El corpus se analiza desde dos perspectivas metodológicas complementarias, que ya han sido aplicadas en varias ocasiones por el autor en el análisis de otro tipo de acontecimientos, normalmente campañas electorales (López-García et al., 2015; López-García, 2016).

- Un análisis cualitativo, desarrollado siguiendo la metodología del análisis del discurso, centrado en dos focos principales de atención:

a) informaciones periodísticas, noticias y análisis difundidos en los medios de comunicación y redes sociales, que dan cobertura a las acciones y declaraciones de representantes de las FFAA y FCSE a lo largo del período analizado. Para ello, se ha realizado un seguimiento de las informaciones en las que participan representantes de las FFAA y FCSE en los magazines matinales de TVE, Antena 3 y Telecinco; informativos nocturnos de estas mismas tres cadenas; prensa digital, centrada inicialmente en cuatro cabeceras que consideramos particularmente representativas, por difusión e influencia (El país, El mundo, El diario, El confidencial), pero extendida eventualmente a otros medios digitales, en relación con búsquedas realizadas a través de Google y noticias visualizadas en la red social Twitter. 
b) las ruedas de prensa del Comité de Gestión Técnica de la crisis del coronavirus, y más concretamente las comparecencias de los representantes de las FFAA, Policía Nacional y Guardia Civil.

Este análisis nos permitirá elaborar un relato complejo que dé cuenta de la presencia mediática de dichas instituciones, así como una evaluación de la misma. Como resultado del mismo, esperamos encontrar respuesta a las preguntas de investigación 1 y 2.

- Un análisis de contenido de nueve cuentas de Twitter a lo largo del período analizado, correspondientes a los principales líderes políticos que protagonizan esta crisis, tanto a nivel nacional como autonómico. Es decir:

- El presidente del Gobierno español y líder del PSOE, Pedro Sánchez.

- Los líderes de los partidos políticos de ámbito nacional que cuentan con grupo parlamentario en el Congreso de los Diputados: Pablo Casado (PP), Santiago Abascal (Vox), Pablo Iglesias (Unidas Podemos y vicepresidente segundo del Gobierno) e Inés Arrimadas (Ciudadanos).

- Los presidentes de cuatro comunidades autónomas, seleccionados tanto por criterios de diversidad ideológica como por su visibilidad mediática durante la crisis: Joaquim Torra (Cataluña, JuntsxCat); Isabel Díaz Ayuso (Comunidad de Madrid, PP); Ximo Puig (Comunidad Valenciana, PSPV-PSOE); e íñigo Urkullu (País Vasco, PNV).

Este análisis busca encontrar tanto referencias a las FFAA, la Guardia Civil y la Policía como usos metafóricos del lenguaje que vinculen la gestión de la crisis del coronavirus con una guerra. Además, también se analiza si las referencias a FFAA y FCSE son positivas o negativas. Estos tres parámetros nos permitirán dar respuesta a la pregunta de investigación 3, y con ello establecer el recorrido completo de esta investigación en lo referente a FFAA y FCSE: su incidencia y valoración no sólo en los medios de comunicación social, sino en los mensajes de los líderes políticos españoles.

\section{Relato de la crisis del Covid-19 en España desde una óptica uniformada}

La estrategia comunicativa del Gobierno, en relación con las FFAA y FCSE, se basa en tres ejes fundamentales:

- La presencia en los medios de comunicación de las acciones de FFAA y FCSE como noticias positivas y que contribuyen a reforzar dicha estrategia de comunicación.

- La presencia de FFAA y FCSE en las ruedas de prensa diarias del Comité de Gestión Técnica de la crisis del coronavirus (en una proporción de tres a dos respecto de los civiles que también participan en estas comparecencias).

- El uso, por parte de los portavoces políticos del Gobierno (y en particular por parte del presidente Pedro Sánchez en sus comparecencias ante la ciudadanía), del lenguaje militar y de abundantes metáforas bélicas, asimilando la crisis sanitaria con una guerra. Se utilizan en abundancia expresiones tales como "guerra contra el virus", "escudo social", "ganar la batalla", "no doblegarse", "resistir", "combatir", "desescalada". Se trata de un empleo metafórico recurrente en política (y en otras esferas discursivas), dado que la guerra permite asentar la gravedad de una situación en las mentes de los receptores, y además es una esfera de conflicto maniqueo, fácil de interpretar y de asimilar (Castelo; Szulman, 2020). Sin embargo, su uso y abuso en una crisis sanitaria como ésta se presta a favorecer interpretaciones falaces (Xifra, 2020).

\subsection{Presencia de las FFAA y FCSE en las noticias}

Desde el inicio del estado de alarma, el papel de las FFAA y FCSE en la crisis pasa a ser prominente. En las acciones y también en la comunicación de los hechos: el Gobierno utiliza la Unidad Militar de Emergencias del ejército español para diversas funciones relacionadas con el virus en lo que pasa a denominarse la "Operación Balmis", mientras la Policía Nacional y la Guardia Civil se despliegan para hacer cumplir las estrictas disposiciones del estado de alarma, que no permiten salir a los españoles de sus casas, salvo para comprar productos de primera necesidad, ir a trabajar si no pueden hacer teletrabajo, ir al médico o pasear al perro.

Los medios dedican singular atención a las acciones de la Unidad Militar de Emergencias del ejército español, así como a cubrir las detenciones de ciudadanos que incumplían las restricciones dictadas por el decreto del estado de alarma por parte de las FCSE. También prestan atención a otros escenarios, como la participación

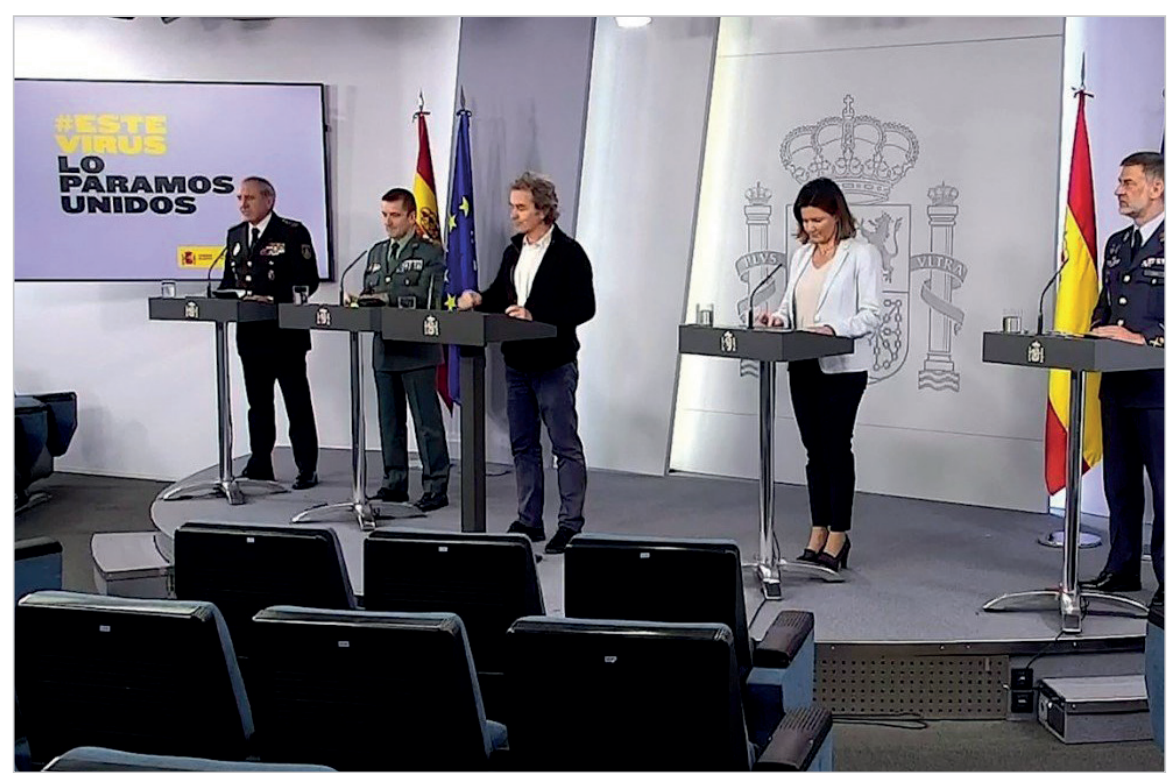

Rueda de prensa del Comité de Gestión Técnica de la crisis del coronavirus. https://www.publico.es/files/article_main/uploads/2020/04/25/5ea44127d3f8b.jpeg 
eventual de las FCSE en los aplausos que cada día se ofrendan desde la sociedad española hacia el personal sanitario. Esta amplia cobertura mediática tiene lugar, casi siempre, en términos inequívocamente positivos y elogiosos para con la acción de FFAA y FCSE:
Los medios de comunicación recibieron con entusiasmo las noticias de FFAA y FCSE montando hospitales de campaña y poniendo multas

a) En lo que se refiere al Ejército español, y más concretamente la UME, la cobertura se centra sobre todo en dos cuestiones:

- montaje del hospital de Ifema (recinto de la feria de muestras) en Madrid y de otros hospitales de campaña; y

- labores de desinfección de residencias, aeropuertos, estaciones de tren e instalaciones similares.

Los medios, en líneas generales, aportan una perspectiva positiva de la labor del Ejército. El hospital de campaña montado en Ifema en Madrid, que tratará a miles de pacientes del Covid-19 (con sintomatología leve), se convierte en uno de los símbolos de la respuesta a la crisis (Telecinco, 1 de abril de 2020: "1.500 colchones, 500 kilos de verduras: las donaciones del milagro de Ifema"). De hecho, gana enteros la figura de la ministra de Defensa, Margarita Robles, que se convierte en la más valorada del Gobierno (El español, 28 de abril de 2020: "La popularidad de Margarita Robles se dispara: primer notable en décadas a un ministro"), tanto por el papel jugado por las FFAA en la "operación Balmis" como por sus declaraciones, en especial su discurso del 22 de abril, con motivo del cierre de la morgue improvisada en el Palacio de Hielo de Madrid, donde la ministra rinde homenaje a las FFAA (20 Minutos, 22 de abril de 2020: "El emotivo discurso de Margarita Robles al cerrar al borde del llanto la morgue del Palacio de Hielo"):

"Lo único que puedo decir, ya sé que no es un consuelo, es que quienes han estado en este palacio, estos hombres y mujeres que han fallecido, no han estado solos. No les hemos podido salvar la vida pero que sepan que, por parte de nuestras Fuerzas Armadas, de la UME, del Ejército de Tierra, siempre han estado con ellos (...) acompañándolos, guardando por su dignidad, por su respeto, orando cuando sabían que eran personas creyentes. Que las familias sepan que no los olvidaremos, que seguro que en otro mundo mejor los estarán viendo, ayudándonos a todos. Y yo no puedo dejar de acompañarlos en ese dolor y de que sepan, que tengan esa seguridad de que no estuvieron solos, porque nuestros hombres y mujeres de las Fuerzas Armadas estuvieron con ellos. Nuestro recuerdo, nuestro cariño, nuestra oración para todos ellos".

Las FFAA se ven envueltas en dos polémicas como resultado de sus actividades. La primera tiene vinculación con la Generalitat de Catalunya, que en varias ocasiones rechaza la ayuda de la UME para desinfectar instalaciones o para montar hospitales de campaña (El país, 8 de abril de 2020: "La Generalitat frena dos hospitales montados por el Ejército y la Guardia Civil en Cataluña"). La segunda deriva de la noticia, anunciada por las propias FFAA el 23 de marzo, de que encontraron varios cadáveres en residencias de Madrid, ancianos que habían fallecido en su residencia sin que, aparentemente, nadie lo notificase (Cadena SER, 23 de marzo de 2020: "El Ejército localiza a ancianos en residencias 'conviviendo' con cadáveres"). Esta noticia, en un momento en el que la gravedad del Covid-19 en las residencias de ancianos sólo comenzaba a intuirse, supuso un shock para la sociedad española y puso en dificultades al gobierno autonómico madrileño, responsable de la gestión de estas residencias.

b) En cuanto a las acciones de la Policía y la Guardia Civil, la imagen que traslucen los medios es que ambos son omnipresentes y se encargan de castigar cualquier exceso de los ciudadanos durante el estado de alarma. Por ello, son abundantes las noticias que, sencillamente, enumeran la cantidad de actuaciones de FCSE, en particular las que conllevan multas. Se destacan, asimismo, imágenes poderosas, como la de un helicóptero de la Guardia Civil que aterriza para comprobar si una mujer que estaba paseando a su perro en Llanes (Asturias) lo hacía cerca de su casa (La nueva España, 4 de abril de 2020: "La Guardia Civil se descuelga en un helicóptero para identificar a una vecina de Llanes que paseaba a su perro"). Pero también encontramos abundantes noticias con inequívoco afán ejemplarizante, como la multa que la policía impone a un ciudadano de un pueblo de la provincia de Valencia que había comprado alimentos que se estimaron in-

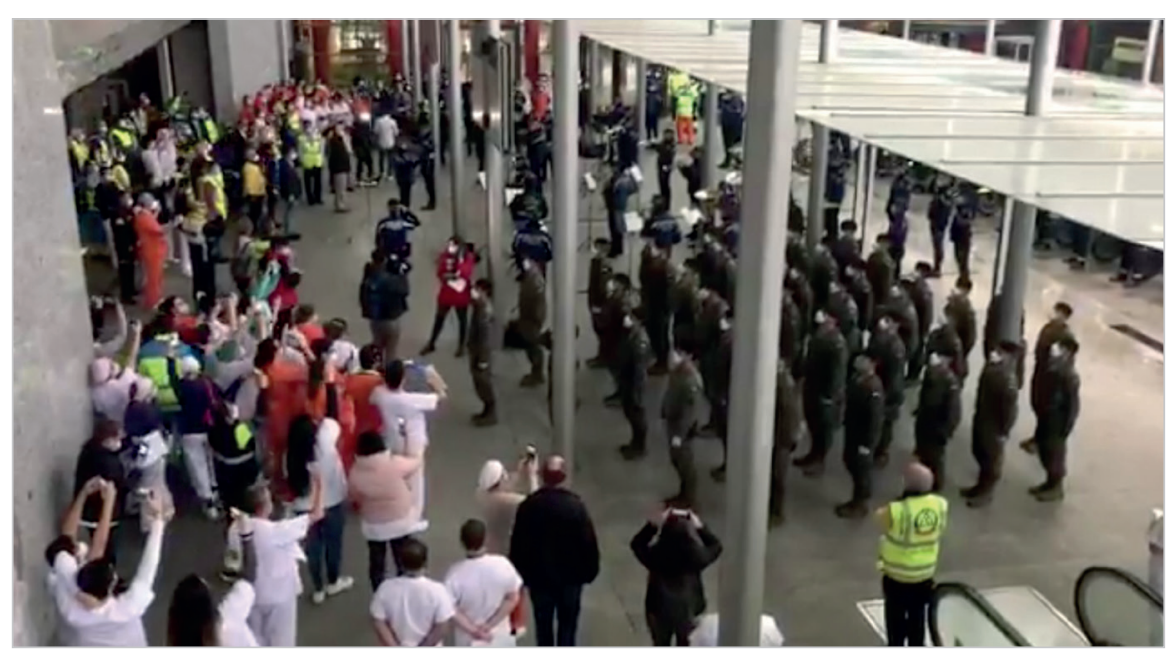

Homenaje de la Policía municipal de Madrid y el Ejército español a los sanitarios del hospital de campaña de Ifema.

https://www.elnacional.cat/es/politica/coronavirus-himno-espana-ifema_491604_102.html 
adecuados (Levante-EMV, 2 de abril de 2020: "Coca-cola, chocolate y salchichas: la compra que le ha costado una multa a un vecino de la Font"):

"La Policía Local de la Font d'en Carròs se ha cansado de la picaresca que utilizan algunos para salir de casa y saltarse la cuarentena. Después de llevar ya muchos días informando a través de diferentes medios (megafonía, cartas en los supermercados, redes sociales, por la calle, etc.), los agentes, para su sorpresa, han descubierto que todavía hay vecinos y vecinas que utilizan hasta límites insospechados las pocas excepciones que dejan las medidas de confinamiento como excusa para poder salir a la calle, prácticamente burlando las normas impuestas por el estado de alarma.

El último ejemplo, y el que ha colmado la paciencia de la policía de este municipio, ha sido el de un vecino que iba por la calle alegando que había ido a comprar al supermercado. Al requerir que enseñara el tíquet, como se está haciendo en muchos casos, los agentes descubrieron que, ni mucho menos, había adquirido productos de primera necesidad, que es una de las excepciones que contempla la cuarentena. La persona había comprado refrescos, chocolate y un paquete de salchichas tipo frankfurt. Como es lógico, fue multado con la cuantía mínima, 601 euros".

Por último, también se destaca el papel de la policía y la Guardia Civil como "animadores" de los ciudadanos y, en particular, del personal sanitario. Es habitual encontrarnos en los diarios digitales, y sobre todo en los informativos de televisión, noticias que muestran a un agente de policía entregando un regalo de cumpleaños a un niño, agentes de la policía o la Guardia Civil que aplauden a los sanitarios en hospitales ( $A B C, 23$ de marzo de 2020: "Coronavirus: aplausos cruzados entre policías y sanitarios a las puertas de un hospital de Valencia"), o que hacen sonar las sirenas ante el aplauso de los vecinos, etcétera.

Las informaciones relacionadas con FFAA y FCSE en los medios españoles no sólo son abundantes, sino que resultan, casi siempre, positivas para sus protagonistas. Las informaciones que presentan sus acciones desde una óptica crítica son minoritarias. Los medios se hacen poco eco, por ejemplo, de las imágenes de abusos policiales que comienzan a difundirse por las redes sociales, y tampoco se plantean (más bien al contrario) la naturaleza de algunas de sus acciones: por ejemplo, si es buena idea congregar a policías y sanitarios en un mismo espacio ante una crisis sanitaria que se enfrenta a un patógeno altamente contagioso; si la policía local tiene potestad para interpretar el decreto del estado de alarma para decidir qué tipo de comida pueden comprar los ciudadanos (algo que no aparece detallado en dicho decreto); o si resulta razonable dedicar los recursos que requiere volar con un helicóptero y hacerlo aterrizar en un entorno rural para comprobar si una persona pasea a su perro adecuadamente; por citar tres noticias a las que se ha hecho ya alusión.

La contestación a esta omnipresencia de las FFAA y de las FCSE en el lenguaje, en las acciones comunicativas y en la información es, por tanto, de pequeño calibre, si atendemos a su presencia en los medios. Rara vez encontramos noticias, en el período cubierto, que dejen en mal lugar esta labor. Encontramos dos grandes excepciones a esta norma. La primera, las informaciones publicadas en algunos medios que se hacen eco de las declaraciones de miembros del Govern de Catalunya, quienes se oponen a la presencia de las FFAA y las FCSE en Cataluña (Nació digital, 18 de marzo de 2020 : "La Generalitat avisa I'Estat: «Desplegar l'exèrcit a Catalunya és innecessari»"); y el escándalo motivado por las declaraciones del general José Manuel Santiago, de la Guardia Civil, que veremos a continuación.

En resumen: las acciones de las FFAA y FCSE concitan el interés de los medios de comunicación, que les dan amplia cobertura, y con una interpretación inequívocamente positiva por parte de los medios en la inmensa mayoría de los casos. La popularidad de estas instituciones y la luz positiva bajo la que se lee su participación en la crisis (apoyo y control de los eventuales excesos o incumplimientos de la ciudadanía) constituyen, sin duda, un elemento que juega a favor de la estrategia de comunicación gubernamental, aunque sin que ello signifique una traslación de la popularidad de estas instituciones hacia el propio Gobierno (con la excepción de la ministra de Defensa). Pero sí es, como mínimo, una forma de concienciar y, al mismo tiempo, coartar a la población con vistas a controlar esta crisis, y también un elemento que nutre de contenidos positivos las informaciones periodísticas.

\subsection{Ruedas de prensa}

Las ruedas de prensa del Comité de Gestión Técnica de la crisis del coronavirus, con periodicidad diaria, ya se estaban produciendo con semanas de antelación a la instauración del estado de alarma. Sin embargo, a partir de ese momento las ruedas de prensa, que eran protagonizadas en exclusiva por parte del doctor Fernando Simón, pasan a convertirse en un evento coral, con cinco participantes:

- Fernando Simón (Director del centro de coordinación de emergencias y alertas sanitarias).

- María José Rallo (Secretaria General de Transportes).

- Miguel Villarroya (Jefe del Estado Mayor de la Defensa, Jemad).

- José Ángel González (Comisario de la Policía Nacional).

- Laurentino Ceña (Teniente General de la Guardia Civil).

La incidencia del coronavirus sobre este Comité es significativa. A partir del 26 de marzo, el general José Manuel Santiago Marín, jefe del Estado Mayor de la Guardia Civil, sustituye a Laurentino Ceña, que ha dado positivo por coronavirus. El día 30, se anuncia que Fernando Simón también ha dado positivo por coronavirus. Le sustituye María José Sierra, 
jefa de área del mismo centro. Simón se reincorpora el 14 de abril. El día 1 de abril, José Ángel González, también enfermo de coronavirus, es sustituido por José García Molina (Subdirector de Logística de la Policía Nacional), quien a su vez cae también enfermo, con lo que la representante de la Policía Nacional, desde el 14 de abril, pasa a ser Pilar Ayué (Subdirectora General de Recursos Humanos).

Estas ruedas de prensa constan de dos partes. La primera es una sucesión de intervenciones de cada uno de los miembros que comparecen, para explicar el estado de la cuestión que les compete, es decir, y siempre con el mismo orden: la evolución diaria de la incidencia de la pandemia (Fernando Simón); acciones

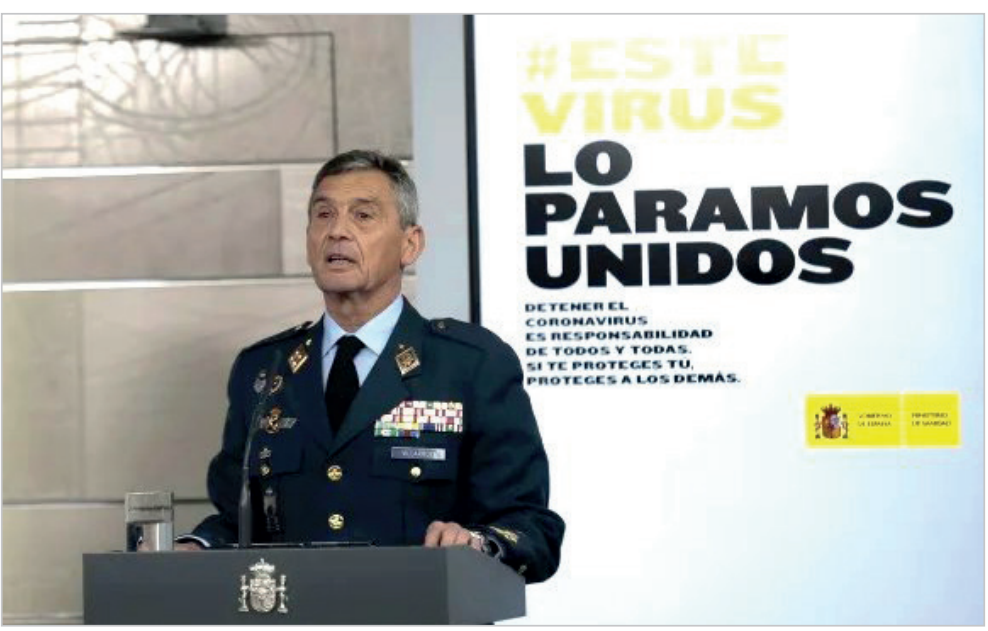

Miguel Villarroya, Jefe del Estado Mayor de la Defensa. https://cutt.ly/8yEyexJ llevadas a cabo desde el Ejército (Miguel Villarroya), la Policía Nacional (José Ángel González) y la Guardia Civil (Laurentino Ceña); y la situación de los transportes y las comunicaciones (María José Rallo). Fernando Simón se encarga de asignar la palabra a cada participante, que suele extenderse unos cinco minutos, con lo que esta comparecencia inicial suele durar unos 25-30 minutos en total.

La segunda parte, las preguntas de los periodistas, está moderada por Miguel Ángel Oliver, Secretario de Estado de Comunicación. Esta moderación suscitó muchas críticas de los medios, y no sólo en estas ruedas de prensa, sino en todas las del Gobierno, por el formato escogido: los periodistas enviaban todas sus preguntas al moderador y éste seleccionaba las que consideraba oportuno. Tras la protesta de los medios, a partir del día 6 de abril se cambia este formato por uno de videoconferencia que permite preguntar en directo a los periodistas, aunque no repreguntar.

Como ya se ha indicado, es llamativa la distribución de participantes en esta rueda de prensa. Se trata de una crisis sanitaria, sin duda. Pero la participación de uniformados de las FFAA y FCSE constituye un claro mensaje en sí mismo. Muestra, por una parte, que la crisis es muy grave, hasta el punto de que de ella participan las FFAA. Una figura que en España ha sido insólita durante décadas, precisamente porque ha estado siempre asociada con situaciones de extraordinaria gravedad, como el golpe de Estado del 23 de febrero de 1981. El valor icónico de los uniformes para certificar la gravedad de una crisis, por otra parte, lleva décadas asentándose sistemáticamente en el imaginario colectivo a través de todo tipo de contenidos de ficción, en particular audiovisuales (películas y series de televisión).

Por otro lado, la presencia de tres representantes vinculados con la seguridad y el control (con el monopolio de la violencia que ejerce el Estado) es suficientemente significativa, en sí misma, para corroborar que la crisis no sólo es seria, sino que, además de un problema sanitario, también constituye un reto para la seguridad de los españoles. Y en este contexto, la presencia de los uniformados, así como el contenido de su comparecencia, funciona en dos direcciones: ofrecer dicha seguridad, pero también advertir al público de que el Estado retiene el control de la situación, y que ejerce con eficacia su capacidad coercitiva (Amoedo-Souto, 2020), como puede deducirse de una comunicación que incide constantemente en el número de multas y detenciones practicadas por las FCSE.

Desde el primer momento, las comparecencias de los representantes de FFAA y FCSE adolecen de importantes dificultades, comunicativamente hablando; queda patente que no son profesionales de la comunicación, ni están acostumbrados a enfrentarse a los medios. Además, los contagios por coronavirus provocan cambios en la portavocía de la Guardia Civil y de la Policía Nacional (dos veces), ahondando en este problema.

Habitualmente, los representantes de FFAA y FCSE leyeron largos comunicados, cuyos contenidos mantienen una estructura muy similar: primero se cuantifican las actuaciones de la institución a la que representan, y después se da paso a narrar algún hecho anecdótico, en un sentido positivo. Es ésta una estructura que probablemente busque compensar, en el caso de los representantes de la Policía Nacional y Guardia Civil, que la exposición inicial haga siempre referencia a acciones coercitivas (multas, detenidos), con anécdotas referidas a hechos positivos, que buscarían demostrar el papel de ambas instituciones para ayudar, y no sólo para vigilar o reprimir, a los ciudadanos.

Por ejemplo, el 30 de marzo el general Santiago desglosa así las acciones llevadas a cabo por la Guardia Civil:

"Las acciones desarrolladas durante el día de ayer por los casi 14.000 guardias civiles que patrullaron los pueblos de España permitieron identificar a 62.056 personas, y proceder a la interceptación de más de 2.100 vehículos. Con motivo de ello, se formularon más de 4.100 denuncias, es decir: un 7,4\% del total de las personas identificadas. 
Tras enumerar, llega el momento, que se reproduce casi todos los días, de narrar alguna anécdota que acerque más a los ciudadanos la labor cotidiana de la Guardia Civil. En esta ocasión, se trata de una pareja de guardias civiles que llevan la comida a los tripulantes de un velero confinado en la costa de Canarias. Otros días se comentan acciones tales como el papel de la Guardia Civil para comprar hielo en una gasolinera, necesario para una intervención quirúrgica, y llevarlo a un hospital, o la interceptación del producto de un robo: 30 kilos de naranjas. El general Santiago comenta así dicha acción, en la rueda de prensa del 13 de abril:

"se imputó un delito de robo a dos individuos, porque éstos se habían apropiado indebidamente de más de treinta kilos de naranjas y limones, que fueron devueltos, gracias a Dios, a su dueño".

En el caso de las FFAA, su representante, el Jemad Miguel Villarroya, se centra en narrar hechos inequívocamente positivos: acciones de la UME y de otras unidades del Ejército para desinfectar residencias, puertos y aeropuertos, o para montar hospitales de campaña.

Villarroya intenta imprimir a sus comunicados un tono bélico, sobre todo en sus primeras comparecencias. Por ejemplo, el sábado 21 de marzo comienza su comunicado diciendo "Hoy es lunes". En el turno de preguntas, el moderador, Miguel Ángel Oliver, le indica a qué se debe el "error". El Jemad responde lo siguiente: "No, no, no. Estoy diciendo que no hay fines de semana en la guerra".

No puede decirse que el Secretario de Estado de Comunicación no conociera de antemano el sentido de las palabras de Miguel Villarroya, porque el día anterior, el viernes 20 de marzo, ya había insistido en ello:

"Hoy es viernes en el calendario. Pero en estos tiempos de guerra o crisis, como queráis llamarlo, todos los días son lunes. El esfuerzo no cesa por el día del calendario, continuaremos todos apoyando a la lucha contra este virus, que nos afecta a todos. Ayer hablé de disciplina, aquí, en esta rueda de prensa, y quiero decir que tengo que felicitar a todos los españoles por la disciplina que están mostrando, todos los ciudadanos comportándose como soldados en este difícil momento".

Y más adelante:

"En esta guerra irregular y rara que nos ha tocado vivir, o luchar, todos somos soldados. Y siguiendo el hilo de ayer, en el que hablaba de alguna de las virtudes militares, hoy me quiero referir al espíritu de servicio. Espíritu de servicio que no es exclusivo de los militares. Al contrario, lo estamos viendo todos los días en el personal sanitario que se desvive por atender a todos aquellos afectados. Eso lo está demostrando día a día, momento a momento, todo el personal de servicio en los hospitales. ¡Hagamos lo mismo! Demostremos que somos soldados; cada uno, en el puesto que nos ha tocado vivir".

La comunicación desplegada por los representantes de FFAA y FCSE, en resumen, planteó varios elementos problemáticos para los objetivos del Gobierno:

- Ofrecían, en la mayoría de los casos, contenidos poco relevantes, que contrastan con las cifras de muertos y el impacto de la epidemia que ha explicado previamente el responsable sanitario (Fernando Simón o María José Sierra), y que acaban acaparando mucho tiempo en las comparecencias.

- La comunicación desplegada por los representantes de las FFAA y FCSE era poco profesional. Se trataba de comunicados poco elaborados, leídos sin mucho énfasis por parte de los portavoces.

- Finalmente, durante las comparecencias los representantes de las FFAA y FCSE incurrieron en revelaciones que dejaban en muy mal lugar al Gobierno, y de las que se harían eco los medios de comunicación. Por un lado, el día 28 de marzo el portavoz de la Policía Nacional, José Ángel González, explicó lo siguiente:

“Hace ya dos meses que el director general de la Policía nos encargó tanto a la Subdirección de Logística [como a la Dirección Adjunta Operativa, DAO] que empezáramos a mover la compra de mascarillas y de guantes".

Esta afirmación chocaba frontalmente con el discurso sostenido por el Gobierno español, que hasta mucho después de la instauración del estado de alarma seguía sin recomendar el uso de mascarillas para la población general. Y que, de hecho, había sido muy criticado por su imprevisión y lentitud en la compra de materiales de protección sanitaria ante la llegada del coronavirus a España. Tanto era así que, de nuevo, el secretario de Estado de Comunicación, Miguel Ángel Oliver, terció, preguntando a José Ángel González si no había querido decir "semanas" en vez de "meses". González se reafirmó en su declaración.

Mucho más grave aún fue la intervención del general de la Guardia Civil José Manuel Santiago, que el 19 de abril responde así a una pregunta sobre el problema de los bulos y fake news que circulan por las redes sociales:

“Decirle que nosotros estamos trabajando con nuestros especialistas en dos direcciones. Una, a través de la Jefatura de Información para tratar de evitar el estrés social que producen todo este tipo de bulos. Otra de las líneas de trabajo es minimizar ese clima contrario a la gestión de la crisis por parte del Gobierno".

La idea de que la Guardia Civil persiga opiniones contrarias al Gobierno, como puede comprenderse fácilmente, resulta explosiva. Y más en el contexto de una crisis de estas características, donde las libertades de los ciudadanos ya estaban recortadas por el estricto confinamiento. Por ese motivo, el ministro del Interior y superior de José Manuel Santiago, Fernando Grande-Marlaska, desmintió ese mismo día la veracidad de estas informaciones, que tildó de "lapsus". 
Pese a ello, no logró parar la crisis de comunicación adicional que le generaron estas declaraciones al Gobierno, duramente atacado por parte de las demás fuerzas políticas y de la mayoría de los medios de comunicación. En particular cuando se supo, poco después, que el comentario del general Santiago estaba sustentado en una iniciativa de la Guardia Civil, ordenada por él mismo, del 15 de abril (Huffington Post, 21 de abril de 2020: "La Guardia Civil pidió por correo identificar bulos que generen 'desafección a instituciones del Gobierno'”).

Finalmente, la negativa repercusión de estas declaraciones hizo que el Gobierno cambiase de estrategia comunicativa, anulando la participación de los representantes de FFAA y FCSE en las ruedas de prensa del Comité de Gestión Técnica de la crisis del coronavirus, que a partir del 26 de abril pasaron a estar protagonizadas exclusivamente, de nuevo, por Fernando Simón.

Como conclusión, puede decirse que la experiencia de incluir tres portavoces uniformados (de las Fuerzas Armadas, la Policía Nacional y la Guardia Civil) de un total de cinco participantes encargados de informar sobre una crisis sanitaria resultó un fracaso desde el punto de vista comunicativo. A pesar del indudable valor icónico de su

Los portavoces de FFAA y FCSE demostraron sus insuficiencias comunicativas en las ruedas de prensa, y le crearon importantes problemas al Gobierno presencia, desde la perspectiva de asentar la gravedad de la crisis y su vertiente de seguridad y control en las mentes de los ciudadanos, las carencias comunicativas y la inexperiencia de dichos portavoces acabó generando problemas mucho más graves al Gobierno que los beneficios que esperaban cosechar con su concurso.

\section{Repercusión de la estrategia de visibilización de FFAA y FCSE en Twitter}

Finalmente, una vez analizado el papel de FFAA y FCSE en la política comunicativa del Gobierno español, tanto en la comunicación emanada directamente desde el mismo como en su repercusión en los medios de comunicación social, conviene prestar atención a su presencia y a la evaluación de sus acciones por parte de los representantes políticos, tanto los afines al Gobierno como los pertenecientes a la oposición política. En la Tabla 2 se muestran los resultados del análisis de contenido efectuado sobre las cuentas de Twitter de nueve dirigentes políticos entre el 15 de marzo y el 25 de abril (se tienen en cuenta tanto tweets propios como retweets).

Tabla 2. Menciones a FFAA y FCSE en las cuentas de Twitter de líderes políticos españoles del 15/03/2020 al 25/04/2020, ambos inclusive

\begin{tabular}{|c|c|c|c|c|}
\hline Dirigente político & Tweets & $\begin{array}{c}\text { Metáforas } \\
\text { bélicas }\end{array}$ & $\begin{array}{c}\text { Mencionan } \\
\text { FFAA y/o FCSE }\end{array}$ & Valoración \\
\hline Pedro Sánchez, presidente del Gobierno (PSOE) & 289 & 15 & 1 & 1 positiva \\
\hline Pablo Iglesias, Vicepresidente segundo del Gobierno (UP) & 169 & 5 & 8 & 7 positiva, 1 negativa \\
\hline Pablo Casado $(P P)$ & 340 & 11 & 13 & 5 positiva, 5 neutra, 3 negativa \\
\hline Santiago Abascal (Vox) & 402 & 1 & 25 & 13 positiva, 2 neutra, 10 negativa \\
\hline Inés Arrimadas (Ciudadanos) & 288 & 2 & 14 & 10 positiva, 2 neutra, 2 negativa \\
\hline Joaquim Torra (Catalunya) & 297 & 1 & 13 & 6 positiva, 4 neutra, 3 negativa \\
\hline Isabel Díaz Ayuso (Madrid) & 322 & 3 & 11 & 7 positiva, 4 neutra \\
\hline Ximo Puig (Comunidad Valenciana) & 117 & 0 & 1 & 1 positiva \\
\hline Íñigo Urkullu (País Vasco) & 220 & 0 & 8 & 7 positiva, 1 neutra \\
\hline
\end{tabular}

Como puede observarse en las cifras generales, la presencia de FFAA y FCSE en estos mensajes de Twitter es pequeña, pero no inexistente. Antes de entrar en cuestiones más específicas, Ilama la atención que, efectivamente, las cuentas del presidente y el vicepresidente segundo del Gobierno tienden a utilizar mucho más las metáforas bélicas que las cuentas de la oposición, con la única excepción de Pablo Casado, que también las emplea, aunque en otra ocasión reprocha al presidente que intente vincular esta crisis con una guerra:

"Sánchez dice que estamos en guerra, pero no es así, esto es una catástrofe en vidas y un drama en empleo. Aquí nadie va a ganar y ya hemos perdido demasiado todos. Más de 20.000 compatriotas fallecidos merecen nuestro respeto, homenaje y luto. Y un minuto de silencio para empezar" (22 de abril de 2020).

Pedro Sánchez incorpora metáforas bélicas en su discurso en quince ocasiones. Se trata de un rasgo muy marcado de sus comparecencias, que también queda reflejado en Twitter con expresiones como "Esta batalla la vamos a ganar" (15 de marzo de 2020), "Todos somos uno en esta lucha" (17 de marzo de 2020), o expresiones que acaban definiendo las medidas del Gobierno, como "escudo social" o "desescalada".

Curiosamente, algunas de las metáforas bélicas empleadas por el vicepresidente Pablo Iglesias sirven para interpelar a otros dirigentes políticos: En una ocasión, Iglesias menciona otro tweet, de la vicealcaldesa de Madrid, Begoña Villacís, que alaba los esfuerzos de las FFAA para montar el hospital de Ifema. Y lo hace en estos términos: "En esta guerra pelea- 
mos todos juntos @begonavillacis Fuerza" (18 de marzo de 2020). En otro tweet, cita las palabras del presidente, Pedro Sánchez:

“Europa debe poner en pie una economía de guerra... Tiene que hacerlo cuanto antes con medidas que respalden el endeudamiento público que estamos asumiendo muchos Estados' El Presidente apunta aquí varias de las claves del momento europeo y mundial" (5 de abril de 2020).

En cambio, el líder de Vox, Santiago Abascal, apenas hace uso de metáforas bélicas en sus mensajes, como tampoco lo hacen Inés Arrimadas ni los presidentes autonómicos analizados.

El balance cambia significativamente si nos fijamos en las menciones directas a la labor de FFAA y FCSE, prácticamente siempre vinculada con la crisis del coronavirus. Las dos cuentas de dirigentes socialistas (el presidente, Pedro Sánchez, y el president de la Generalitat Valenciana, Ximo Puig) prácticamente no hacen mención de estos colectivos en sus mensajes. En cambio, el resto de las cuentas analizadas sí que se prodigan en este particular. Entre el $3 \%$ y el $6 \%$ del total de mensajes de dichas cuentas, según los casos, contiene referencias a la labor de FFAA y FCSE. Puede parecer una cifra pequeña, pero hay que insistir en una obviedad: esta es una crisis sanitaria, y la faceta de la seguridad y el control resulta, en principio, una cuestión secundaria, aunque no carezca de relevancia.

Por contraste con Pedro Sánchez, el vicepresidente, Pablo Iglesias, sí que llena su discurso de alabanzas a los militares, a menudo en relación con iniciativas del ejército en ciudades gobernadas por "sus" alcaldes (José María González, 'Kichi', en Cádiz; Ada Colau en BarceIona).

El líder del PP, Pablo Casado, sí que hace mención de las FFAA y FCSE como un factor positivo en esta crisis, en reconocimiento de su labor. Encontramos algunos mensajes negativos, que aparecen como consecuencia de las declaraciones del general José Manuel Santiago, ya comentadas, que desataron una tormenta política.

En cuanto a Santiago Abascal, líder de Vox, su cuenta de Twitter hace constantes referencias elogiosas a los militares y a la Guardia Civil (muchas más que a los sanitarios, de hecho), habitualmente combinadas con alabanzas a la monarquía (el Jefe del Estado también es el comandante supremo de las Fuerzas Armadas), que se truncan en acerbas críticas con el escándalo de las declaraciones del general Santiago, interpretadas como muestra de un golpe de Estado que estaría dando el Gobierno (interpretación que, por otra parte recorre todo el timeline de Abascal desde el momento en que comienza el estado de alarma):

“iALARMA DEMOCRÁTICA! Un general de la Guardia Civil anuncia que está trabajando en 'minimizar el clima contrario a la gestión del gobierno. Esto es, de hecho, el inicio de un golpe de Estado del propio gobierno, que ordena al Instituto Armado que vulnere la Constitución" (19 de abril de 2020).

Inés Arrimadas, presidenta de Ciudadanos, hace también muchas referencias elogiosas al Ejército y la Guardia Civil, habitualmente centradas en las acciones que desarrollan en Cataluña, que demostrarían su utilidad y popularidad entre la 
población, frente al desinterés de los nacionalistas catalanes por contar con ellos.

El president de la Generalitat de Catalunya, Joaquim Torra, incorpora continuas referencias elogiosas a los Mossos d'Esquadra (lo mismo sucede con Urkullu y la Ertzaintza), combinadas con mensajes indicando las órdenes que el propio Torra ha transmitido a los Mossos d'Esquadra, que éstos ejecutan. Una imagen de control y poder en un momento en que el Estado ha intervenido las competencias sanitarias de la Generalitat. El Ejército y la Guardia Civil, en cambio, no aparecen nunca en su discurso, salvo para aludir al escándalo del general Santiago.

Por último, la presidenta de la Comuni-

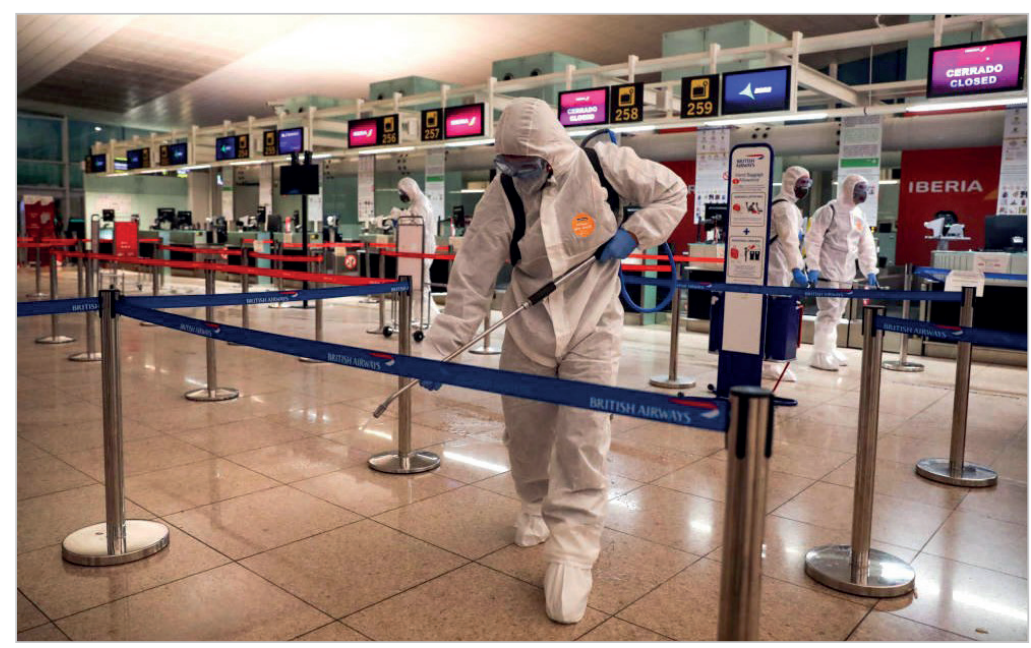

Miembros de la UME desinfectan el aeropuerto de El Prat, Barcelona https://cutt.ly/4yEyL7q

dad de Madrid, Isabel Díaz Ayuso, muestra cierta evolución temporal. En los mensajes iniciales no hay referencias a las FFAA ni a las FCSE, a pesar del papel del ejército en el montaje del hospital de Ifema. Posteriormente sí que se produce ese reconocimiento.

\section{Conclusiones}

A lo largo de esta investigación hemos analizado el papel que tuvieron las FFAA y FCSE españolas en la estrategia de comunicación del Gobierno español, desplegada durante los primeros cuarenta días del estado de alarma, coincidentes con la fase aguda de la primera oleada de la pandemia del coronavirus SARS-CoV-2. Estas fechas coinciden también con el periodo en el que se celebraron las ruedas de prensa diarias del Comité de Gestión Técnica de la crisis del coronavirus con la presencia de representantes del Ejército español, la Policía Nacional y la Guardia Civil.

Se trata, en conjunto, de una situación insólita, tanto por la crisis como por el papel jugado en ella por parte de FFAA y FCSE. Además, se trata de un acontecimiento muy cercano en el tiempo. Precisamente por ello, hemos intentado ser cautos en la hipótesis y preguntas de investigación, así como en las metodologías empleadas.

Nuestra hipótesis de partida defendía que el Gobierno privilegiaba la presencia de noticias y portavoces pertenecientes a las FFAA y FCSE como parte de su estrategia de comunicación. Los resultados de nuestro análisis avalan que, en efecto, así fue: el papel de estos colectivos en las informaciones periodísticas, en la estrategia de gestión de la crisis desplegada por parte del Gobierno español, así como en su lenguaje (plagado de referencias bélicas), y por último en las propias ruedas de prensa encargadas de informar diariamente a los españoles de la evolución de la pandemia, lo muestran con claridad.

En relación con esto, podemos dar también respuesta a la primera de nuestras preguntas de investigación (P1): ¿Cómo se refleja la actividad de FFAA y FCSE en los medios de comunicación? El balance es en general positivo, tanto desde el punto de vista de estas instituciones como desde la estrategia comunicativa del Gobierno: los medios informan profusamente de sus actividades, y casi siempre lo hacen en un sentido positivo. Su omnipresencia mediática, además, permite difundir la sensación entre la población de que la crisis a la que se enfrentan es grave y de que, frente a ella, el Gobierno retiene el control de la situación, al menos en términos coercitivos, y no dudará en ejercer dicho control sobre la población, como atestiguan las abundantes informaciones sobre el número de multas o de detenidos por parte de las FCSE a lo largo del confinamiento, que se presentan casi siempre en términos positivos, e incluso aleccionadores para con quienes incumplen las normas. Las FFAA y FCSE sirven, así, como vehículo de "domesticación" de los medios (Bennett; Lawrence; Livingston, 2007). También funcionan, en un sentido más amplio, como representación de la ubicuidad del poder, su capacidad para llegar a todas partes, para verlo todo, para vigilar que toda la población siga las restricciones del estado de alarma. La representación mediática de FFAA y FCSE nos remite, en efecto, a la noción de disciplina y control que describe Foucault (1975): un control que se ejerce desde la capacidad de vigilar y desde la certidumbre del castigo en el caso de que no se cumplan las instrucciones.

Nuestra hipótesis también establecía que las limitaciones comunicativas de los representantes de las FFAA y FCSE, al no ser especialistas en comunicar situaciones de crisis, y al no estar vinculados, en puridad, con la auténtica naturaleza de dicha crisis (la gestión sanitaria de una pandemia), generarían problemas a la estrategia de comunicación del Gobierno español. Esta parte de la hipótesis queda validada, al menos parcialmente, como se deduce del análisis de las ruedas de prensa. Y también respondemos, con ello, a la segunda pregunta de investigación (P2): ¿Qué y cómo comunican las FFAA 
y FCSE en las ruedas de prensa del Comité de Gestión Técnica de la crisis del coronavirus?

El problema que queda evidenciado en el análisis es que los portavoces de FFAA y FCSE acaban aportando demasiada comunicación sin que haya apenas nada que comunicar, y sin que los que comunican sepan comunicar. Así que comunican a menudo informaciones absolutamente irrelevantes o secundarias, y más en el contexto de una crisis como ésta. Comunican sin profesionalidad, pues claramente no son personas acostumbradas a exponer en público en las condiciones que se les pide. Y comunican demasiado, lo cual da lugar a errores de envergadura. Finalmente, el Gobierno, que buscaba escudarse en los militares, policía y Guardia Civil, mostrar eficacia y control y dificultar las críticas a su gestión desde la oposición, acaba enfrentándose a una crisis política de gran relevancia, derivada de las declaraciones del general José Manuel Santiago (Costa-Sánchez; López-García, 2020).

Por último, y por lo que se refiere a la tercera pregunta de investigación (P3): ¿Cómo evalúan los líderes políticos españoles las acciones de FFAA y FCSE?: Los datos del análisis de contenido, inevitablemente exploratorios, muestran resultados poco concluyentes, desde la perspectiva de analizar el éxito o fracaso de la estrategia comunicativa del Gobierno de cara a los líderes de otros partidos. La estrategia de vinculación de la crisis del coronavirus con una guerra apenas logra asentarse en el discurso de los demás líderes políticos. En cambio, sí que son habituales las referencias, en general positivas, a FFAA y FCSE, en reconocimiento de su labor, y en este sentido puede decirse que casi todos los políticos se "suben al carro", aunque sea centrándose en sus propias fuerzas de seguridad de ámbito autonómico. En todo caso, este reconocimiento no impide que también surjan críticas, aunque sean dirigidas, en realidad, al Gobierno, cuando estalla el escándalo motivado por las declaraciones del general Santiago.

Paradójicamente, el exceso de comunicación en las ruedas de prensa jugó en contra del éxito comunicativo de FFAA y FCSE

\section{Referencias}

Amat, Francesc; Arenas, Andreu; Falcó-Gimeno, Albert; Muñoz, Jordi (2020). "Pandemics meet democracy. Experimental evidence from the Covid-19 crisis in Spain". SocArXiv, 6 April. https://doi.org/10.31235/osf.io/dkusw

Amoedo-Souto, Carlos-Alberto (2020). "Del Fast and Furious al Jurassic Park. Divagaciones de un jurista alarmado sobre el régimen sancionador del estado de alarma". Webinar Derecho público y Covid-19, 24 abril.

Bennett, W. Lance; Lawrence, Regina G.; Livingston, Steven (2007). When the press fails: Political power and the news media from Iraq to Katrina. Chicago: University of Chicago Press. ISBN: 9780226042855

Besalú, Reinald (2020). "Pandemia y medios de comunicación convencionales". En: Gutiérrez-Rubí, Antoni; Pont-Sorribes, Carles (coords.). Comunicación política en tiempos de coronavirus. Barcelona: Cátedra Ideograma-UPF de Comunicación Política y Democracia, pp. 104-108. ISBN: 9798637554812

Campo-Fort, Alfredo; Crespo-Esbert, Juanjo; García-De-Torres, Elvira; Latorre-Vázquez, Rubén (2016). "La comunicación de crisis en el área de seguridad y defensa". En: Chávez, Manuel; Mercado, María-Teresa (eds.). La comunicación en situaciones de riesgo y crisis, pp. 155-180. Valencia: Tirant Humanidades. ISBN: 9788416349715

Campos-Domínguez, Eva (2017). "Twitter y la comunicación política”. El profesional de la información, v. 26, n. 5, pp. 785-793.

https://doi.org/10.3145/epi.2017.sep.01

Canel-Crespo, María-José (2009). “El impacto de los sucesos imprevistos en la imagen pública de los gobiernos españoles". Anàlisi, n. 38, pp. 219-236.

https://ddd.uab.cat/pub/analisi/02112175n38/02112175n38p219.pdf

Capdevila-Gómez, Arantxa; Moragas-Fernández, Carlota (eds.) (2019). Usos políticos de la metáfora. Medios, instituciones y ciudadanía en la definición de conflictos en la esfera pública. Barcelona: Icaria. ISBN: 9788498889314

Casero-Ripollés, Andreu (2020). "Impact of Covid-19 on the media system. Communicative and democratic consequences of news consumption during the outbreak". El profesional de la información, v. 29, n. 2, e290223.

https://doi.org/10.3145/epi.2020.mar.23

Castelo, Santiago; Szulman, Martin (2020). "El framing en la crisis". En: Gutiérrez-Rubí, Antoni; Pont-Sorribes, Carles (coords.). Comunicación política en tiempos de coronavirus. Barcelona: Cátedra Ideograma-UPF de Comunicación Política y Democracia, pp. 28-32. ISBN: 9798637554812

Chadwick, Andrew (2013). The hybrid media system: Politics and power. Oxford: Oxford University Press. ISBN: 9780 190696733 
Chávez, Manuel; Mercado, María-Teresa (eds.) (2016). La comunicación en situaciones de riesgo y crisis. Valencia: Tirant Humanidades. ISBN: 9788416349715

Chiang, Wen-Yu; Duann, Ren-Feng (2007). “Conceptual metaphors for SARS: 'war' between whom?”. Discourse \& society, v. 18, n. 5, pp. 579-602.

https://doi.org/10.1177/0957926507079631

Centro de Investigaciones Sociológicas (2015). 3080/0-0. Barómetro de abril 2015. Frecuencias de preguntas cruzadas por variables políticas.

http://datos.cis.es/pdf/Es3080rei_A.pdf

Coombs, Timothy (2014). Ongoing crisis communication: Planning, managing, and responding. New York: Sage Publications. ISBN: 9781412983105

Costa-Sánchez, Carmen; López-García, Xosé (2020). “Comunicación y crisis del coronavirus en España. Primeras lecciones". El profesional de la información, v. 29, n. 3, e290304.

https://doi.org/10.3145/epi.2020.may.04

Foucault, Michel (1975). Surveiller et punir: naissance de la prison. Paris: Gallimard. ISBN: 9782070291793

Gutiérrez-Rubí, Antoni; Pont-Sorribes, Carles (coords.) (2020). Comunicación política en tiempos de coronavirus. BarceIona: Cátedra Ideograma-UPF de Comunicación Política y Democracia. ISBN: 9798637554812

https://www.upf.edu/documents/220602201/233560922/Definitiu+Comunicaci\%C3\%B3n+Coronavirus/1c1d3def-34ae-fe5d-0019-ef40c936b0e3

Ibáñez, Ángel (2016). "La comunicación de las Administraciones Públicas en España en situaciones catastróficas o de emergencia”. En: Chávez, Manuel; Mercado, María Teresa (eds.). La comunicación en situaciones de riesgo y crisis. Valencia: Tirant Humanidades. ISBN: 9788416349715

Lázaro-Rodríguez, Pedro; Herrera-Viedma, Enrique (2020). “Noticias sobre Covid-19 y 2019-nCoV en medios de comunicación de España: el papel de los medios digitales en tiempos de confinamiento". El profesional de la información, v. 29, n. 3, e290302.

https://doi.org/10.3145/epi.2020.may.02

Lee, Kaman (2009). "How the Hong Kong government lost the public trust in SARS: Insights for government communication in a health crisis". Public relations review, v. 35, n. 1, pp. 74-76.

https://doi.org/10.1016/j.pubrev.2008.06.003

López-García, Guillermo (2016). “'New' vs 'old' leaderships: the campaign of Spanish general elections 2015 on Twitter". Communication \& society, v. 29, n. 3, pp. 149-168.

https://doi.org/10.15581/003.29.3.149-168

López-García, Guillermo (2017). “Comunicación política y discursos sobre el poder”. El profesional de la información, v. 26, n. 4, pp. 573-578.

https://doi.org/10.3145/epi.2017.jul.01

López-García, Guillermo; Gámir Ríos, José; García-Ull, Francisco; Llorca-Abad, Germán; Cano-Orón, Lorena; González-Esteban, José-Luis (2015). "El debate sobre Europa en Twitter. Discursos y estrategias de los candidatos de las elecciones al Parlamento Europeo de 2014 en España”. Revista de estudios políticos, n. 170, octubre-diciembre, pp. $213-246$. https://doi.org/10.18042/cepc/rep.170.07

Moreno-Castro, Carolina (ed.) (2009). Comunicar los riesgos. Ciencia y tecnología en la sociedad de la información. Madrid: Biblioteca Nueva. ISBN: 9788497429269

Mueller, John (1970). "Presidential popularity from Truman to Johnson". American political science review, v. 64, n. 1, pp. 18-34.

https://doi.org/10.2307/1955610

Suau-Gomila, Guillem; Percastre-Mendizabal, Salvador-José; Palà-Navarro, Gemma; Pont-Sorribes, Carles (2017). "Análisis de la comunicación de emergencias en Twitter. El caso del Ébola en España". En: Sierra, Javier. Uso y aplicación de las redes sociales en el mundo audiovisual y publicitario, pp. 119-130. Madrid: McGrawhill Education, pp. 119-131. ISBN: 9788448613587

Xifra, Jordi (2020). “Comunicación corporativa, relaciones públicas y gestión del riesgo reputacional en tiempos del Covid-19". El profesional de la información, v. 29, n. 2, e290220.

https://doi.org/10.3145/epi.2020.mar.20

Yan, Jin; Pang, Augustine; Cameron, Glen (2006). "Strategic communication in crisis governance: Singapore's management of the SARS crisis". Copenhagen journal of Asian studies, v. 23, n. 1, pp. 81-104.

https://doi.org/10.22439/cjas.v23i1.693 